\title{
Aligning innovations in health funding with innovations in care
}

\author{
Noah M. Ivers MD PhD, Irfan Dhalla MD MSc, Adalsteinn Brown DPhil
}

Cite as: CMAJ 2018 August 13;190:E957-60. doi: 10.1503/cmaj.171312

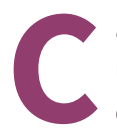

anada has been called the land of the pilot project. ${ }^{1}$ It is not uncommon for a promising, innovative model of care to disappear or stagnate after the project or grant-based funding finishes - or the willingness of a clinician or researcher to put in extra hours dries up. ${ }^{2}$ This seems especially true of innovations that support patients transitioning from one sector of the health system to another (e.g., from hospital to community). Yet projects that allow different parts of the health care system to work together more efficiently are exactly the type of innovations we need. To ensure that pilot projects that successfully improve integration and coordination of care become routine, changes may be needed to how health care provider organizations are funded. Funding strategies must reflect how care should be organized rather than reinforcing how it is currently organized.

Funding strategies can encourage or hinder the uptake of evidence-based health care delivery. Although we often focus on who pays for health care (i.e., private v. public), how we fund health care providers also deserves attention. Successful pilots for new models of care often involve different personnel or new technology, and existing funding strategies may limit health care provider organizations' ability to adopt them.

\section{How does health care funding affect the way health care is delivered?}

Health care is frequently funded in silos. For example, hospitals are often paid separately from physicians who work entirely inside them, and both are paid separately from primary care providers and from home care. Personal support and prescription medications for long-term care residents are paid for out of separate budgets. These silos create barriers for implementing ways of delivering care that may work better. For example, without a careful analysis, it may seem that paying for relatively cheap services in one area is simply "extra resource consumption" to deliver additional services, even though doing so may result in decreases in relatively expensive services elsewhere. ${ }^{3}$ Streamlining and improving the care of patients with chronic conditions requires investment in both interdisciplinary primary care ${ }^{4}$ and evidence-based medications. ${ }^{5}$ Yet, any savings from reduced admissions and complications accrue not to the primary care organizations who had to invest addi-

\section{KEY POINTS}

- The way health care providers - both individuals and organizations - are funded can either encourage or hinder uptake of best practices.

- Siloed budgets make it especially difficult to implement and scale innovations that would improve integration of care.

- Health systems around the world are experimenting with novel funding strategies to incentivize delivery of high-value care.

- Canada should experiment with and evaluate initiatives that seek to align innovations in funding strategies with innovations that better integrate care.

tional resources to deliver high-quality care, but likely to nearby hospitals.

Hospitals often use their budgets to deliver acute care at full capacity, leaving little flexibility to invest in new models such as enhanced outpatient care that may lead to reduced costs to the health system, even if those models are well grounded in evidence. Pilot studies have shown that, once in hospital, patients may benefit from support for self-management through patient education and navigation after hospital discharge, and that this may be cost-saving. ${ }^{6,7}$ Yet, the organization paying for the patient navigators cannot reap the rewards if the visits or admissions averted are realized by a different organization. A recently completed multisite trial in Ontario showed that a series of supportive phone calls over the course of a year can help patients who have had a myocardial infarction to adhere to their recommended management plan. ${ }^{8}$ However, if a hospital found the resources to invest in delivering this type of intervention as an ongoing program for the population in its region, it is not assured of reaping the rewards.

As currently configured, no single key player in Canadian health systems is well positioned both to make the investment in an innovative model of care and to easily claim back the financial benefits, which is a barrier to innovation. Structural consolidation at the regional level, to ensure a more centralized approach for delivering or organizing a model to integrate care, would allow for economies of scale. However, this will require deconstruction of the siloed, provider-level health care budget. 


\section{How do specific funding models support or hinder innovation?}

Global hospital budgets typically involve a stable, predetermined annual dollar figure to cover the health services delivered. Although they enable a predictable approach to controlling costs, and allow for managerial flexibility since the funding is not linked to specific items or activities, global budgets do not incentivize innovation and arguably incentivize complacency.

An alternative funding mechanism known as "activity-based funding" offers a set price for a specific type of hospital admission, so the hospital is paid per patient. Forms of this model have been adopted in many jurisdictions around the world and in Canada (including Ontario, Quebec, British Columbia and Alberta) despite uncertainty around their impact on quality of care. ${ }^{9}$ This model of funding encourages more efficient in-hospital care (because hospitals will lose money if they overspend), which may translate into reduced lengths of stay or better access. However, the funding model may also contribute to overtreatment, and more postdischarge problems or higher posthospital costs. Activity-based funding strategies do not generally incentivize the implementation of models of care that span sectors and time.

A more sophisticated approach, often described as "bundled care," aims to encourage collaboration across sectors to better manage transitions in a way that benefits patients at lower overall costs. ${ }^{10}$ In general, this involves a set price for a full "episode of care" that can span several health care provider organizations and sectors, such as assessment, surgery and rehabilitation for joint replacement. Penalties for potentially avoidable and costly posttreatment events (e.g., readmissions) are sometimes added to accentuate the incentives for coordinating postdischarge care. ${ }^{11-13}$ Funding innovations such as bundled care respond to a key insight into the relation between cost and quality, which is that, although high-quality care may ultimately cost less, the costs and benefits of improving quality are often spread out over time and across a range of individuals and organizations. ${ }^{3,14}$ Emerging evidence on bundled care offers tentative support for its ability to improve value in a specific set of contexts or for specific procedures. ${ }^{15-18}$ Ideally, the "bundles" must cover an adequate length of time to encourage implementation of models of care that support patients over the long term. ${ }^{10}$ Whether bundled care funding models can help improve functional outcomes in complex patients in addition to encouraging more efficient single-disease-oriented care remains uncertain. ${ }^{19}$

Activity-based funding addresses each hospital admission with a set price for each patient interaction; bundled care focuses on "episodes" with a set price covering the key steps on the pathway from acute presentation to postacute rehabilitation. Policy-makers are now beginning to experiment with payment methods that address individuals with one or more chronic diseases, over a longer period. These "population-based-payment" models involve a price paid per person in a defined community, adjusted by risk profiles for that community, for a given period (e.g., one year). Capitation-based models are increasingly common in primary care, ${ }^{20}$ but population-based payment models that include multiple sectors are much more rare. The provid- ers - including hospitals and physician groups - share responsibility and any monetary gains (and sometimes losses) in the care of this population. ${ }^{21}$ The jury is still out on these approaches: such initiatives show promise 22 but have not consistently achieved better patient experience and population outcomes at lower costs. ${ }^{23,24}$ Major challenges include governance, adequate assessment of the funding needs for the targeted population, and provider accountability for (and capability of) improving outcomes that matter to patients.

\section{What are some risks of making changes to how health providers are funded?}

There may be unintended consequences to the adoption of any new funding strategy. Cherry-picking patients - that is, selecting less complex, more profitable patients for procedures over more complex patients for whom outcomes and costs are more unpredictable - and "up-coding" patients (i.e., describing patients in a manner that renders them eligible for higher payments) are ways that health care providers can benefit financially from activitybased funding or bundled payment reforms., ${ }^{9,25,26}$ Shifting organizational priorities in a way that does not reflect patient need is another. ${ }^{4,13}$ For example, if hospitals earn more money for patients who receive home care postdischarge, they may make a referral for all patients regardless of need, thereby increasing costs for the health system in a manner not consistent with anticipated benefit. Such responses threaten the goals of the funding reforms by increasing total health system costs without improving population health.

Incentives for physicians must be considered especially carefully. When wait times are longer than acceptable, funding models that incentivize volume (i.e., fee-for-service) remain sensible. However, as with activity-based funding for organizations, funding models for individual health professionals that encourage more care do not necessarily encourage better care. Furthermore, research on physician pay-for-performance schemes indicates a lack of patient benefit. ${ }^{27-30}$ Ideally, funding strategies should encourage appropriate care for the complex patients who need it most, while mitigating the risk of unintended consequences. Coordinating care across specialties and settings in a highly integrated system is the best way to ensure that care is delivered appropriately, and physician pay-for-performance interventions do not tend to achieve this.

\section{Can new funding strategies encourage integration of care?}

If current siloed approaches to funding health care disincentivize the cross-sectoral investments in care that could benefit both patients and payors, then what kind of funding could encourage innovative models of care that improve integration across sectors and care for patients? A recent debate pitted advocates of bundled care against a population-based health funding approach (i.e., using capitation-based models to fund population groups). Those advocating for expansion of bundled funding approaches argue that these strategies can effectively send 
appropriate price signals to encourage spread and scale of costeffective interventions. ${ }^{31}$ Those advocating for population-based funding approaches emphasized the importance of aligning incentives to encourage investments in prevention and disease management. ${ }^{32}$

The debate obscured an important point, though, specifically that improvement may not happen unless both funding and delivery of care are integrated. Bundled care has promise, but the cross-sectoral partners that share the "bundle" must be willing and able to work together to find mutually beneficial solutions. ${ }^{31}$ One sector or professional group alone is unlikely to be able to lead a process that requires different parts of the health system to work together to facilitate efforts for improvement and system sustainability. Relatedly, funding announcements that focus on a single sector - like home care - rather than on a health goal or population may dissuade spread and scale innovations seeking to integrate and coordinate care.

Regional budget-holding organizations (such as regional health authorities) could be a responsible party able both to invest in system-integration models and to reap their rewards but only if they control comprehensive, cross-sectoral budgets. For example, in some jurisdictions, responsibility for both home care and other health services have been devolved to the regional level..$^{33}$ The hope is that local governance and oversight can enable better coordination across the health care system and greater focus on preventive services, allowing for integrated services or investment in nonhealth services that affect health outcomes. ${ }^{34}$ Such a model may enable the regional budgetholder to realize more clearly the benefits of making iterative investments in improvement over time - once the hard work of achieving consensus is achieved. ${ }^{35}$

Canada is blessed with a well-trained, highly capable clinician workforce. Increasingly, that workforce is developing capacity in quality improvement, but as clinicians aim to tackle problems of integration of care, they come up against barriers to spread and scale that may seem insurmountable due to misaligned or siloed funding mechanisms. We recommend that Canada's provincial governments facilitate integration of care by deliberately moving away from siloed funding and testing options with the explicit aim of incentivizing all relevant stakeholders to collaborate in the management of their populations ${ }^{36}$ that require care in multiple settings over time. This could be attempted in an incremental fashion through systematic experiments with bundled payments, initially for common surgical procedures with clear potential for standardization, then expanding based on lessons learned to a wider range of procedures and conditions covering longer patient-episodes and involving a greater number of providers. ${ }^{37} \mathrm{~A}$ more transformative option would be to experiment with population-based payments, managed by integrated provider organizations with oversight of all hospital- and community-based services and providers as well as medications, starting in communities where there is a natural hospital hub that provides the bulk of secondary care for a population, and an identifiable group of primary care providers willing and able to engage. Either approach must involve the necessary support and reserved time for the devel- opment of the governance and accountability structures that engage all the relevant providers.

Importantly, we also recommend ongoing federal and provincial investment in the infrastructure required for more integrated and coordinated models of care to succeed: capacity building among clinicians in leading quality-improvement initiatives; e-health capabilities to enable continuity of information and to capture relevant outcomes; and support for embedded, rigorous, formative and summative program evaluations. Such evaluations could build on the approaches used by the Center for Medicare \& Medicaid Innovation; ${ }^{38}$ success could be guided by measurement of patient (and provider) experience, population health and $\operatorname{cost}^{39}-$ but also by the identification of lessons learned to be applied to the next experiment. Policy-makers should view investments in the infrastructure needed to integrate care and experiments testing novel payment strategies as a long-term project, an iterative process informed by emergent population or health system needs, to be refined over time based on the results of rigorous evaluations.

\section{References}

1. Begin M, Eggertson L, Macdonald N. A country of perpetual pilot projects. CMAJ 2009;180:1185.

2. Dhalla IA, Majumdar SR. Should we take the C-Traln to reduce hospital readmissions? J Gen Intern Med 2014;29:1432-3.

3. Øvretveit J. Does improving quality save money? A review of evidence of which improvement to quality reduce costs for health service providers. London (UK): The Health Foundation; 2009.

4. Vojta D, Koehler TB, Longjohn M, et al. A coordinated national model for diabetes prevention: linking health systems to an evidence-based community program. Am J Prev Med 2013;44(Suppl 4):S301-6.

5. Booth GL, Bishara P, Lipscombe LL, et al. Universal drug coverage and socioeconomic disparities in major diabetes outcomes. Diabetes Care 2012;35:2257-64.

6. Taylor SJC, Pinnock H, Epiphaniou E, et al. A rapid synthesis of the evidence on interventions supporting self-management for people with long-term conditions: PRISMS - Practical systematic Review of Self-Management Support for longterm conditions. Health Services and Delivery Research, No. 2.53. Southampton (UK): NIHR Journals Library; 2014.

7. Valaitis RK, Carter N, Lam A, et al. Implementation and maintenance of patient navigation programs linking primary care with community-based health and social services: a scoping literature review. BMC Health Serv Res 2017;17:116.

8. Ivers N, Schwalm JD, Witteman HO, et al. Interventions Supporting Long-term Adherence aNd Decreasing cardiovascular events (ISLAND): pragmatic randomized trial protocol. Am Heart J 2017;190:64-75.

9. Palmer KS, Agoritsas T, Martin D, et al. Activity-based funding of hospitals and its impact on mortality, readmission, discharge destination, severity of illness, and volume of care: a systematic review and meta-analysis. PLoS One 2014;9:e109975.

10. Navathe AS, Song Z, Emanuel EJ. The next generation of episode-based payments. JAMA 2017;317:2371-2.

11. Wasfy JH, Zigler CM, Choirat C, et al. Readmission rates after passage of the hospital readmissions reduction program: a pre-post analysis. Ann Intern Med 2017;166:324-31.

12. Desai NR, Ross JS, Kwon JY, et al. Association between hospital penalty status under the hospital readmission reduction program and readmission rates for target and nontarget conditions. JAMA 2016;316:2647-56.

13. Ryan AM, Krinsky S, Adler-Milstein J, et al. Association between hospitals' engagement in value-based reforms and readmission reduction in the Hospital Readmission Reduction Program. JAMA Intern Med 2017;177:862-8.

14. Marshall M, Øvretveit J. Can we save money by improving quality? BMJ Qual Saf 2011;20:293-6.

15. Tsai TC, Greaves F, Zheng J, et al. Better patient care at high-quality hospitals may save Medicare money and bolster episode-based payment models. Health Aff (Millwood) 2016;35:1681-9.

16. Dummit LA, Kahvecioglu D, Marrufo G, et al. Association between hospital participation in a Medicare bundled payment initiative and payments and quality outcomes for lower extremity joint replacement episodes. JAMA 2016;316: 1267-78. 
17. Navathe AS, Troxel AB, Liao JM, et al. Cost of joint replacement using bundled payment models. JAMA Intern Med 2017;177:214-22.

18. Hussey PS, Mulcahy AW, Schnyer C, et al. Closing the quality gap: revisiting the state of the science (vol. 1: bundled payment: effects on health care spending and quality). Evid Rep Technol Assess (Full Rep) 2012;(208.1):1-155.

19. Upshur RE, Tracy S. Chronicity and complexity: Is what's good for the diseases always good for the patients? Can Fam Physician 2008;54:1655-8.

20. Glazier RH, Klein-Geltink J, Kopp A, et al. Capitation and enhanced fee-for-service models for primary care reform: a population-based evaluation. CMAJ 2009; 180:E72-81.

21. Huynh TM, Baker GR, Bierman A, et al. Exploring accountable care in Canada: integrating financial and quality incentives for physicians and hospitals. Ottawa: Canadian Foundation for Healthcare Improvement; 2014.

22. Lupiañez-Villanueva F, Theben A. Strategic Intelligence Monitor on Personal Health Systems Phase 3 (SIMPHS3). Gesundes Kinzigtal (Germany). Luxembourg (Belgium): Publications Office of the European Union; 2014. Available: http://publications.jrc.ec .europa.eu/repository/bitstream/JRC93763/jrc93763.pdf (accessed 2018 June 21).

23. Blackstone EA, Fuhr JP Jr. The economics of Medicare accountable care organizations. Am Health Drug Benefits 2016;9:11-9.

24. Smith N, Church J. Shifting the lens: the introduction of population-based funding in Alberta. Healthc Manage Forum 2008;21:36-42.

25. Bevan G, Hood C. What's measured is what matters: targets and gaming in the English public health care system. Public Adm 2006;84:517-38.

26. Fonarow GC, Konstam MA, Yancy CW. The hospital readmission reduction program is associated with fewer readmissions, more deaths: time to reconsider. J Am Coll Cardiol 2017;70:1931-4.

27. Cashin C, Chi Y-L, Smith P, et al., editors. Paying for performance in health care: implications for health system performance and accountability. Geneva: World Health Organization; 2014. Available: www.euro.who.int/_data/assets/ pdf_file/0020/271073/Paying-for-Performance-in-Health-Care.pdf (accessed 2018 Feb. 20).

28. Lapointe-Shaw L, Mamdani M, Luo J, et al. Effectiveness of a financial incentive to physicians for timely follow-up after hospital discharge: a population-based time series analysis. CMAJ 2017;189:E1224-9.

29. Lavergne MR, Law MR, Peterson S, et al. A population-based analysis of incentive payments to primary care physicians for the care of patients with complex disease. CMAJ 2016;188:E375-83.

30. Rudoler D, de Oliveira C, Cheng J, et al. Payment incentives for communitybased psychiatric care in Ontario, Canada. CMAJ 2017;189:E1509-16.

31. Porter ME, Kaplan RS. How to pay for health care. Harv Bus Rev 2016;94:88-100 Available: https://hbr.org/2016/07/how-to-pay-for-health-care (accessed 2018 May 22).

32. James BC, Poulsen GP. The case for capitation. Harv Bus Rev 2016;94:102-11. Available: https://hbr.org/2016/07/the-case-for-capitation (accessed 2018 May 22).

33. Taking charge of health and social care in Greater Manchester: the plan. Manchester (UK): Greater Manchester Combined Authority; 2015. Available: https://www. greatermanchester-ca.gov.uk/downloads/file/125/taking_charge_of_our_health _and_social_care_in_greater_manchester (accessed 2018 Feb. 20).

34. Walshe K, Coleman A, McDonald R, et al. Health and social care devolution: the Greater Manchester experiment. BMJ 2016;352:i1495.

35. Lorne C, Coleman A, McDonald R, et al. Researching health and social care devolution: learning from Greater Manchester. Manchester (UK): University of Manchester; 2016. Available: www.health.org.uk/sites/health/files/GM\%20 HSC\%20devolution\%20interim\%20findings\%20-\%201-3-2017.pdf (accessed 2018 May 22).

36. Sutherland JM, Hellsten E. Integrated funding: connecting the silos for the healthcare we need. Commentary No. 463. Toronto: C.D. Howe Institute; 2017. Available: www.cdhowe.org/sites/default/files/attachments/research_papers/ mixed/Commentary_463.pdf (accessed 2018 May 22).

37. Struijs JN, Baan CA. Integrating care through bundled payments - lessons from The Netherlands. N Engl J Med 2011;364:990-1.

38. Rajkumar R, Press MJ, Conway PH. The CMS Innovation Center - a five-year self-assessment. N Engl J Med 2015;372:1981-3.

39. Bodenheimer T, Sinsky C. From triple to quadruple aim: care of the patient requires care of the provider. Ann Fam Med 2014;12:573-6.
Competing interests: Noah Ivers reports grants from Canadian Institutes of Health Research and the Government of Ontario, outside the submitted work. Irfan Dhalla reports that his affiliation, Health Quality Ontario, has an institutional interest in advancing some of the ideas discussed in this article. No other competing interests were declared.

This article has been peer reviewed.

Affiliations: Women's College Research Institute and Institute for Health System Solutions and Virtual Care (Ivers), Women's College Hospital; Department of Family and Community Medicine (Ivers), University of Toronto; Institute of Health Policy, Management and Evaluation (Ivers, Dhalla), Dalla Lana School of Public Health, University of Toronto; Health Quality Ontario (Dhalla); Department of Medicine (Dhalla), St. Michael's Hospital and University of Toronto; Dalla Lana School of Public Health (Brown), University of Toronto, Toronto, Ont.

Contributors: All of the authors contributed substantially to the conception and design of the work. Noah Ivers and Adalsteinn Brown drafted the manuscript. All of the authors critically revised the manuscript for important intellectual content, gave final approval of the version to published and agreed to be accountable for all aspects of the work.

Acknowledgements: Noah Ivers is supported by salary awards in the form of a New Investigator Award in Community-Based Primary Health Care from the Canadian Institutes of Health Research and a Clinician Scientist Award from the Department of Family and
Community Medicine at the University of Toronto, and has helped develop and evaluate a number of cross-sectoral qualityimprovement initiatives. Irfan Dhalla is a vicepresident at Health Quality Ontario and has experience implementing and evaluating cross-sectoral models of care. Adalsteinn Brown is Interim Dean of the Dalla Lana School of Public Health and a former official in the Government of Ontario.

Disclaimer: The opinions expressed in this publication do not necessarily represent the opinions of Health Quality Ontario or any of the other organizations with which the authors are involved. No endorsement is intended or should be inferred.

Correspondence to: Noah Ivers, Noah.Ivers@ wchospital.ca 